\title{
Dual inhibition of FOXM1 and its compensatory signaling pathway decreased the survival of ovarian cancer cells
}

\author{
DAE WOO LEE ${ }^{1}$, WEONSUN LEE ${ }^{2}$, MIYEON KWON ${ }^{2}$ and HAE NAM LEE ${ }^{1}$ \\ ${ }^{1}$ Department of Obstetrics and Gynecology and ${ }^{2}$ Clinical Medicine Research Institute, Bucheon St. Mary's Hospital, \\ College of Medicine, The Catholic University of Korea, Seoul 14647, Republic of Korea
}

Received March 4, 2020; Accepted October 6, 2020

DOI: $10.3892 /$ or.2020.7845

\begin{abstract}
The present study aimed to analyze the compensatory signaling pathways induced by forkhead domain inhibitor-6 (FDI-6), which is a forkhead box protein M1 (FOXM1) inhibitor, in ovarian cancer cells and evaluate the effectiveness of simultaneous inhibition of FOXM1 and the compensatory signaling pathway in decreasing the survival of ovarian cancer cells. The present study identified the proteins involved in the compensatory mechanism activated by FDI-6 in HeyA8 ovarian cancer cells using western blot analysis and a reverse-phase protein array. In addition, a cell viability assay was performed to determine the effects of FDI- 6 and the compensatory signaling pathway on cancer cell viability. All experiments were performed in three-dimensional cell cultures. The present study observed that FDI- 6 stimulated the upregulation of N-Ras, phosphoprotein kinase C 8 (p-PKC8) (S664) and HER3 in HeyA8 cells. Tipifarnib as an N-Ras inhibitor, rottlerin as a p-PKCS (S664) inhibitor and sapitinib as a HER3 inhibitor were selected. The combination of FDI- 6 with tipifarnib attenuated the upregulation of N-Ras induced by FDI- 6 and the combination of FDI- 6 with sapitinib also attenuated HER3 downstream signaling pathway in HeyA8 cells, as shown by on western blot analysis. Rottlerin downregulated p-PKCס (S664) by inhibiting the activity of a Src-related tyrosine kinase that transfers a phosphate group to $\mathrm{PKC} \delta$. Compared with FDI-6 alone, the addition of tipifarnib or rottlerin to FDI-6 was significantly more effective in reducing the growth of HeyA8 cells. However, the combination of FDI-6 and sapitinib did not induce a significant decrease in survival of HeyA8 cells. In conclusion, the addition of tipifarnib or rottlerin to inhibit N-Ras or p-PKCס (S664), respectively, inhibited the compensatory signaling pathway response induced by FDI-6
\end{abstract}

Correspondence to: Dr Hae Nam Lee, Department of Obstetrics and Gynecology, Bucheon St. Mary's Hospital, College of Medicine, The Catholic University of Korea, 327 Sosa-ro, Wonmi-gu, Bucheon-si, Gyeonggi-do, Seoul 14647, Republic of Korea

E-mail: leehn@catholic.ac.kr

Key words: compensatory adaptive response, forkhead box protein M1, N-Ras, phosphoprotein-PKCס (S664), ovarian cancer in HeyA8 cells. These inhibitors increased the efficacy of FDI-6, which inhibits FOXM1, in reducing ovarian cancer cell viability.

\section{Introduction}

Epithelial ovarian cancer is the most lethal gynecological cancer and the seventh most commonly diagnosed cancer among females worldwide (1). Worldwide, a total of 230,000 females are diagnosed and 150,000 die from the disease (2). The main reasons for failure in the treatment of ovarian cancer are late presentation, high recurrence and drug resistance (3). Many patients with stage III or IV ovarian cancer who show complete response to frontline treatment eventually show high recurrence rates (3). Several studies have focused on lowering the high recurrence and drug-resistance rates and improving survival of patients with ovarian cancer $(4,5)$. The Cancer Genome Atlas project has analyzed mRNA expression, microRNA expression, promoter methylation and DNA copy number in high-grade serous ovarian cancer tissues, and pathway analyses suggested that forkhead box protein M1 (FOXM1) signaling is involved in serous ovarian cancer pathophysiology (4). This project determined that the FOXM1 transcription factor network was significantly altered in $87 \%$ of cases and FOXM1 and its proliferation-related target genes were consistently overexpressed. The transcription factor FOXM1 binds to sequence-specific motifs on DNA through its DNA-binding domain and activates proliferation- and differentiation-associated genes (6). Aberrant overexpression of FOXM1 plays an important role in cancer progression and oncogenesis (7). Decreased FOXM1 expression by inhibitor activity significantly inhibited ovarian cancer cell migration/invasion and tumor growth in vitro and in vivo (8).

The major obstacle in the management of ovarian cancer is drug resistance, and compensatory adaptive response is one of the mechanisms that cause drug resistance $(5,9)$. This response in cancer cells modulated the cell signaling pathway related to cell survival and activates the drug resistance process, which ultimately can lead to the survival of cancer cells during drug therapy. Thus, the addition of a secondary drug that can hinder the compensatory adaptive response may increase the effectiveness of ovarian cancer treatment by reducing the viability of cancer cells. Previously, we confirmed that pS6 is activated 
by the compensatory adaptive response to paclitaxel in HeyA8 and SKOV3 ovarian cancer cells and inhibiting pS6 increased the efficacy of paclitaxel in reducing the survival of cancer cells (5). Inhibition of FOXM1 may decrease ovarian cancer growth, however, the compensatory adaptive response induced by FOXM1 inhibition interrupts effective treatment. In addition to FOXM1, the inhibition of compensatory adaptive response induced by FOXM1 inhibitor may be more effective in the treatment of ovarian cancer.

Normal epithelial cells form well-organized cell layers with the help of the extracellular matrix, and additional supplements from the extracellular matrix are required to regulate the normal process of epithelial cell proliferation, differentiation and survival (10). Since two-dimensional cell culture is not optimal to explain the mechanisms by which cancer cells survive and proliferate, three-dimensional (3D) cell culture models, which mimic the in vivo environment more accurately compared with two-dimensional cell cultures, are used in epithelial tumor cell studies to assess the consecutive processes of cancer initiation and cancer cell proliferation (10-12).

The present study used 3D cell cultures to analyze the compensatory signaling pathway to FOXM1 inhibition in ovarian cancer cells and assessed the additional effectiveness of inhibition of FOXM1 in decreasing the survival of ovarian cancer cells. Forkhead domain inhibitor-6 (FDI-6) was selected as the FOXM1 inhibitor. FDI- 6 binds directly to FOXM1 to displace FOXM1 from its genomic targets and induce concomitant transcriptional downregulation (6).

\section{Materials and methods}

Cells. HeyA8, CAOV3, OVCAR3 and SKOV3 ovarian cancer cell lines derived from humans were used. CAOV3 (cat. no. 30075), OVCAR3 (cat. no. 30161) and SKOV3 (cat. no. 30077) cells were purchased from the Korean Cell Line Bank. CAOV3, OVCAR3 and SKOV3 cells were derived from a human ovarian adenocarcinoma. HeyA8 cells were a kind gift from a laboratory of the Department of Systems Biology, MD Anderson Cancer Center, Houston, TX, USA. The HeyA8 cells originated from a human ovarian cancer xenograft (HX-62) that was developed from a peritoneal metastatic mass of a patient with moderately differentiated papillary cystadenocarcinoma of the ovary (13).

Cell culture. All cancer cell lines were maintained in RPMI-1640 medium (Gibco; Thermo Fisher Scientific, Inc.) containing 10\% FBS (Gibco; Thermo Fisher Scientific, Inc.), streptomycin $(10,000 \mu \mathrm{g} / \mathrm{ml})$, penicillin $(10,000 \mathrm{U} / \mathrm{ml})$ and amphotericin $\mathrm{B}(25 \mu \mathrm{g} / \mathrm{ml})$ at $37^{\circ} \mathrm{C}$ in humidified atmosphere with $5 \% \mathrm{CO}_{2}$. For the 3D culture, each well of a 96- or 12-well plate were coated with thawed Matrigel (Growth Factor Reduced Matrigel; Corning Inc.) and seeded with ovarian cancer cells. A total of $1 \times 10^{4}$ HeyA8, CAOV3, and OVCAR3 cells/well were seeded in a 12-well plate coated with Matrigel, and the 3D structures attained $80 \%$ confluence after 4 days of incubation. During the FDI-6 (Axon Medchem) treatment, the FBS content of the medium was changed to $2 \%$. The plates were kept inside an incubator at $37^{\circ} \mathrm{C}$ for $24 \mathrm{~h}$ for western blot analysis, cell viability assay and RPPA analysis. Inhibitors of proteins involved in the compensatory signaling pathway were simultaneously supplied with FDI-6 to the ovarian cancer cells. N-Ras, phosphoprotein kinase C-delta (p-PKCס) (S664), and HER3 were selected as proteins involved in the compensatory adaptive response. The present study used tipifarnib (Cayman Chemical Company) for N-Ras inhibition, rottlerin (Abcam) for p-PKCS (S664) inhibition and sapitinib (Selleck Chemicals) for HER3 inhibition. Tipifarnib, a farnesyl transferase inhibitor interferes with Ras function by inhibition of farnesyl transferase, the enzyme coupling a 15-carbon isoprenyl group to Ras proteins (14). Rottlerin is a protein kinase inhibitor and inhibits $\mathrm{PKC} \delta$ by interacting with its ATP-binding site (15). Sapitinib is an EGFR/ErbB family inhibitor, which induces apoptosis in the sensitive cell lines and suppresses phosphorylated (p)-EGFR and its downstream pathways in a dose-dependent manner (16). HER3 possesses impaired kinase activity and preferably heterodimerizes with HER2. HER3-HER2 heterodimerization activates downstream signaling pathways that regulate several cellular processes including cell proliferation, cell survival, apoptosis, tumor growth, and metastasis (17).

Cell viability assay. Cell viability was analyzed using Cell Counting Kit-8 (CCK-8; Dojindo Molecular Technologies, Inc.) according to the manufacturer's instructions. A total of $1 \times 10^{3}$ HeyA 8 and CAOV3 cells and $1 \times 10^{4}$ SKOV 3 cells were seeded into a 96-well plate for the cell viability assay. FDI-6 was added to each cell culture on day 4 . The culture medium was removed and $100 \mu \mathrm{l}$ fresh medium containing $10 \mu \mathrm{l}$ CCK-8 solution was added to each well. The cells were then placed in a $37^{\circ} \mathrm{C}$ incubator for $4 \mathrm{~h}$. The optical density values were determined in triplicate at a wavelength of $450 \mathrm{~nm}$. The cell viability was analyzed in ovarian cancer cells after treatment with FDI-6 alone $(0,3$ and $10 \mu \mathrm{M})$ with one inhibitor of $\mathrm{N}-\mathrm{Ras}, \mathrm{p}-\mathrm{PKC} \delta$ (S664), and HER3 (0, 3 and $10 \mu \mathrm{M})$ and with the combination of FDI- 6 and an inhibitor.

RPPA analysis. RPPA analysis was performed to identify proteins involved in the compensatory adaptive response induced by FDI- 6 in HeyA8 cells. RPPA analysis is a high-throughput method that allows the measurement of protein expression levels in a large number of samples simultaneously using $>200$ validated antibodies. A total of $1 \times 10^{4}$ HeyA8 cells/well were seeded in a 12 -well plate for RPPA analysis. FDI- 6 was added to each cell culture on day 6 . HeyA8 cells were treated with FDI-6 at concentrations of 1, 10 and $20 \mu 1$ on day 6 . All tests were performed in duplicate. After thawing Matrigel by adding $800 \mu \mathrm{l} 1 \mathrm{X}$ Hank's balanced salt solution with $5 \mathrm{mM}$ ethylenediaminetetraacetic acid to each well, the cells were lysed by mixing 30-100 $\mu 1$ lysis buffer [1\% Triton X-100, 50 mM HEPES (pH 7.4), $150 \mathrm{mM}$ $\mathrm{NaCl}, 1.5 \mathrm{mM} \mathrm{MgCl}{ }_{2}, 1 \mathrm{mM}$ EGTA, $100 \mathrm{mM} \mathrm{NaF} 10 \mathrm{mM}$ $\mathrm{Na}$ pyrophosphate, $1 \mathrm{mM} \mathrm{Na} \mathrm{VO}_{3}, 10 \%$ glycerol] with the cell pellet followed by centrifugation at $18,470 \mathrm{x} \mathrm{g}$ and $4^{\circ} \mathrm{C}$ for $10 \mathrm{~min}$. The bicinchoninate method was used to measure protein concentration. A total of $10 \mu \mathrm{l}$ SDS sample buffer [40\% glycerol, 8\% SDS, $0.25 \mathrm{M}$ Tris- $\mathrm{HCl}(\mathrm{pH} 6.8)$ and $\beta$-mercaptoethanol) was added to $30 \mu 1$ supernatant and heated to $95^{\circ} \mathrm{C}$ for $5 \mathrm{~min}$. Protein lysate concentrations were adjusted to $1 \mu \mathrm{g} / \mu \mathrm{l}$, and a serial dilution of five concentrations was prepared, with $10 \%$ of the samples replicated for quality 
control (2470 Arrayer; Aushon Biosystems Inc.) on nitrocellulose-coated slides (Grace Bio-Labs). Immunostaining was performed using a DakoCytomation-catalyzed system (Dako; Agilent Technologies, Inc.) and diaminobenzidine colorimetric reaction. Spot intensities were analyzed and quantified using MicroVigene software (version 3.0, VigeneTech Inc.) to generate spot signal intensities. Data from the RPPA analysis were rearranged by the rank sum score method and are expressed in a heat map in which green indicates downregulation and red indicates upregulation of protein expression. The heat map was generated using Cluster 3.0 (http://bonsai.hgc. $\mathrm{jp} / \sim \mathrm{mdehoon} /$ software/cluster/software.htm) as a hierarchical cluster using Pearson's correlation coefficient and a center metric.

Western blot analysis. A total of $1 \times 10^{4}$ HeyA8, CAOV3, and OVCAR3 cells/well and $1 \times 10^{5}$ SKOV 3 cells/well were seeded in a 12-well plate for western blot analysis. FDI-6 was added to each cell culture on day 4. Ovarian cancer cell lysates were prepared using RIPA buffer (Thermo Fisher Scientific, Inc.). Protein concentration was determined through the Lowry method using a DC protein assay kit (Bio-Rad Laboratories, Inc.) following the manufacturer's protocol. Protein samples $(5 \mu \mathrm{g})$ were separated using $8-12 \%$ SDS-PAGE and transferred to a polyvinylidene difluoride membrane (Amersham; Cytiva). The membrane was pre-incubated with 5\% skimmed milk in TBS for $1 \mathrm{~h}$ at room temperature. Membranes were incubated with primary antibodies against FOXM1 (cat. no. 5436; Cell Signaling Technology, Inc.), HER3 (cat. no. 12708; Cell Signaling Technology, Inc.), N-Ras (cat. no. sc-31; Santa Cruz Biotechnology, Inc.), p-PKC $\delta$ (S664) (cat. no. sc-365463; Santa Cruz Biotechnology, Inc.), PKC $\delta$ (cat. no. ab18216; Abcam), and $\beta$-actin (cat. no. A5441; Sigma-Aldrich; Merck KGaA) were diluted 1:1,000 in TBS with $0.1 \%$ Tween-20 (TBS-T) overnight at $4{ }^{\circ} \mathrm{C}$ and then washed three times with TBS-T. Following which, membranes were incubated with HRP-conjugated goat anti-rabbit IgG antibody (1:5,000; cat. no. BR170-6515; Bio-Rad Laboratories, Inc.) or goat anti-mouse IgG antibody (1:5,000; cat. no. BR170-6516; Bio-Rad Laboratories, Inc.) for $1 \mathrm{~h}$ at room temperature. The membrane was washed in TBS-T, and hybridized bands were detected using an ECL clarity detection kit (Bio-Rad Laboratories, Inc.) and ChemiDoc XR analyzer software Image Lab 5.1 (Bio-Rad Laboratories, Inc.).

Chromatin isolation. HeyA8 cells were grown in 100-mm dishes to $80 \%$ confluence prior to FDI-6 (1, 3 and $10 \mu \mathrm{M})$ or $0.1 \%$ DMSO control treatment for $24 \mathrm{~h}$. For chromatin isolation, cells were harvested using a chromatin extraction kit (Abcam) according to the manufacturer's protocol. First, cells were cross-linked with $1 \%$ formaldehyde in $10 \mathrm{ml}$ culture media by rocking at $50 \mathrm{rpm}$ for $10 \mathrm{~min}$ at room temperature and added to $1.1 \mathrm{ml}$ of $1.25 \mathrm{M}$ glycine. Subsequently, cells were harvested by scraping into cold PBS and centrifuged at $20,500 \mathrm{x}$ g for $5 \mathrm{~min}$ at $4^{\circ} \mathrm{C}$. Cell pellets were lysed sequentially with lysis buffer and resuspended in extraction buffer containing protease inhibitors. Samples were homogenized on ice using a Q125 sonicator (Qsonica; Misonix, Inc.) for $2 \mathrm{~min}$ at medium power with a pulse of $20 \mathrm{sec}$ on $/ 30 \mathrm{sec}$ off and centrifuged at $13,570 \mathrm{xg}$ for $10 \mathrm{~min}$ at $4^{\circ} \mathrm{C}$. The supernatant was collected and dialyzed in chromatin buffer at a 1:1 ratio. Protein concentration was measured using a DC protein assay kit (Bio-Rad Laboratories, Inc.) according to the manufacturer's protocol. Protein samples $(5 \mu \mathrm{g})$ were separated using 8-10\% SDS-PAGE and further analyzed using western blot analysis. Incubation with primary antibody against FOXM1 (1:1,000), histone H3 (1:5,000; cat. no. ab1791; Abcam) and GAPDH (cat. no. A9545; Sigma-Aldrich; Merck KGaA) was performed overnight at $4^{\circ} \mathrm{C}$.

ATP measurement. HeyA8 cells were seeded in 12-well plates and treated with 0,3 and $10 \mu \mathrm{M}$ rottlerin for $24 \mathrm{~h}$. Cells were washed with cold PBS and total ATP levels were measured in cell lysates using a Colorimetric ATP Assay kit (cat. no. ab83355; Abcam) according to the manufacturer's protocol. Briefly, cells were resuspended in $100 \mu \mathrm{l}$ ATP assay buffer, centrifuged at $13,000 \mathrm{x}$ g for $5 \mathrm{~min}$ at $4^{\circ} \mathrm{C}$ and protein was removed from the supernatant using Deproteinizing Sample Preparation kit (cat. no. ab204708; Abcam). A total of $40 \mu \mathrm{l}$ deproteinated samples were added to the ATP reaction mix in 96-well clear plates and incubated at room temperature for $30 \mathrm{~min}$ in the dark. The absorbance of samples was measured using a VersaMax microplate reader (Molecular Devices, LLC) at a wavelength of $570 \mathrm{~nm}$ and the results were calculated relative to the standard curve.

Microscopic imaging analysis. Images of ovarian cancer cells following treatment with FDI-6 and inhibitors for $24 \mathrm{~h}$ were captured under $\times 100$ magnification using an inverted microscopy (CKX41; Olympus Corporation).

Statistical analysis. One-way ANOVA and Tukey's Honest Significant Difference test was applied to evaluate the differences in cell viability and protein expression. All statistical analyses were performed using SPSS (version 20; IBM Corp.). $\mathrm{P}<0.05$ was considered to indicate a statistically significant difference.

\section{Results}

Protein expression after FOXM1 inhibition on ovarian cancer cells. FOXM1 expression was assessed in several ovarian cancer cells in order to select the cells for use in subsequent experiments. FOXM1 expression was the highest in HeyA8 cells based on western blot analysis (Fig. 1A). FOXM1 expression was also observed in CAOV3 and OVCAR3 cells, but the expression level was rather low in SKOV3 cells. Hence, HeyA8 and $\mathrm{CAOV} 3$ cells were selected for subsequent experiments and SKOV3 cells were used as controls. FDI-6 inhibited FOXM1 function by displacing FOXM1 from its genomic targets in HeyA8 cells (Fig. 1B). Western blot analysis on chromatin fractions revealed a specific displacement of DNA-bound FOXM1 following treatment with FDI-6. RPPA analysis was performed to identify the proteins associated the adaptive signaling pathway response induced by FDI-6 in HeyA8 cells (Fig. 2). In cells treated with the highest concentration of FDI-6 $(20 \mu \mathrm{M})$, the concentration of DMSO was $0.1 \%$, and the concentration of DMSO in the control was also $0.1 \%$. When cells were treated with a lower concentration of FDI-6, less DMSO was included and the effect of DMSO on cells was minimized (Fig. 2C). Different concentrations of DMSO may 
B
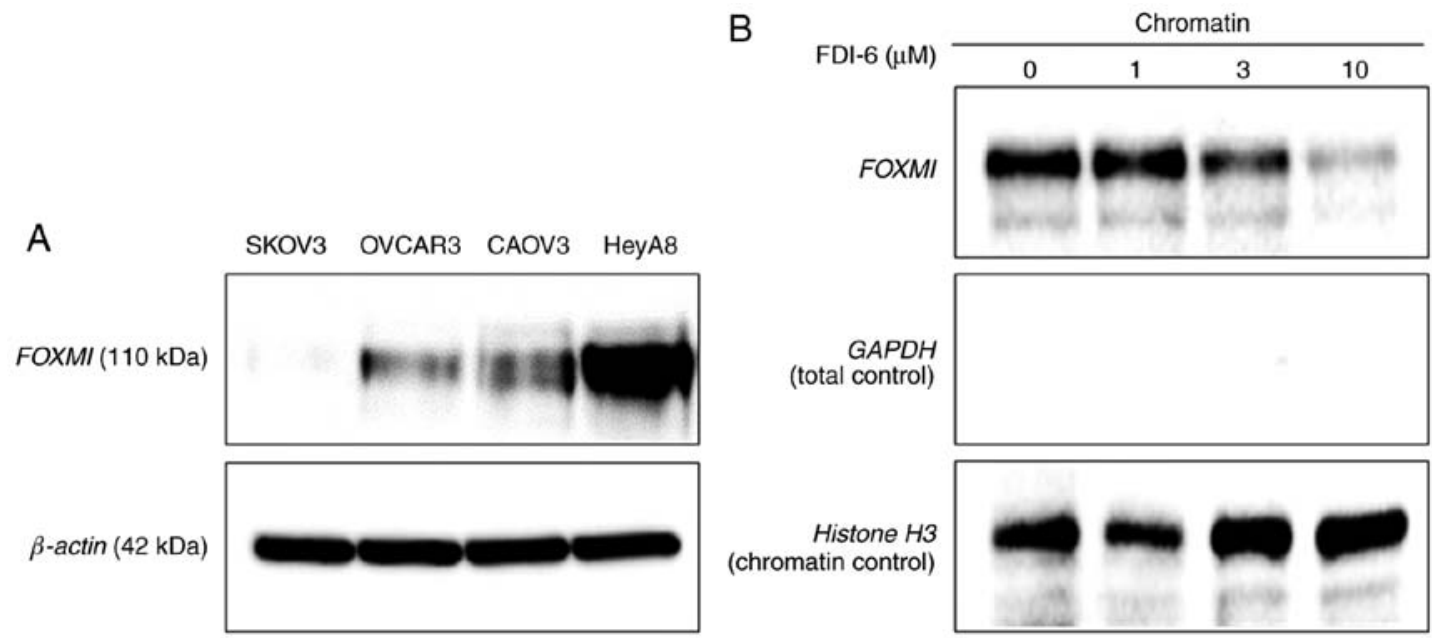

Figure 1. FOXM1 expression in ovarian cancer cells and FOXM1 inhibition by FDI-6 in HeyA8 cells. (A) Western blot analysis of FOXM1 expression in ovarian cancer cell lines. (B) Western blot analysis of FOXM1 in chromatin fractions of HeyA8 cells treated with FDI-6 in three-dimensional cell culture. FOXM1, forkhead box protein M1; FDI-6, forkhead domain inhibitor-6.

cause an initial decrease in expression of these proteins at low doses of FDI-6. As shown in Fig. 2A and B, proteins with a high expression level after inhibition of FOXM1 are displayed in red in the upper part of the heat map, and proteins with low or no expression are shown in green in the lower part of the heat map. In the heat map, the proteins are arranged according to the degree of expression from top to bottom. Proteins with a high expression level (in red) and associated with the cell signaling pathway were chosen first. Bak and $\mathrm{Bcl} 2$ are apoptotic proteins and were excluded from candidate proteins. Validation by western blot analysis identified the proteins with different expression levels from those shown in RPPA analysis, and these were also excluded. Smad4 was shown to be differently expressed on western blot analysis and was excluded (data not shown). After these processes, N-Ras, p-PKCD (S664) and HER3 were chosen as candidate proteins and $\mathrm{PKC} \delta$ was added to normalize the signals obtained using p-PKCס (S664) (Fig. 3).

Dual inhibition of FOXM1 and a protein involved in the compensatory signaling pathway induced by FOXM1 inhibition. Increased N-Ras expression induced by FDI-6 in HeyA8 cells was weakened in CAOV3 cells, and p-PKCס (S664) and HER3 even showed decreased levels compared with HeyA8 cells (Fig. 3B). CAOV3 cells showed lower expression of FOXM1 (Fig. 1A) compared with HeyA8 cells and may be one of the reasons for differences in the expression of N-Ras, p-PKC (S664) and HER3 between HeyA8 and CAOV 3 cells. Only N-Ras in CAOV3 cells was selected as a candidate protein. Tipifarnib as an N-Ras inhibitor, rottlerin as a p-PKCס (S664) inhibitor and sapitinib as a HER3 inhibitor at concentrations of 3.33 and $10 \mu \mathrm{M}$ were treated in HeyA8 cells to validate their ability to inhibit N-Ras, p-PKC (S664) and HER3 expression. The combination of FDI-6 with tipifarnib attenuated the upregulation of N-Ras induced by FDI- 6 in HeyA8 and CAOV3 cells (Fig. 4A and D). The combination of FDI-6 with sapitinib attenuated p-Akt, which is one of the proteins associated with the HER3 downstream signaling pathway but did not attenuate HER3 expression in HeyA8 cells
(Fig. 4B). Sapitinib suppresses p-EGFR and its downstream pathways (16). Rottlerin downregulated p-PKC $($ S664) by inhibiting the activity of the kinase that transfers a phosphate group to PKC $\delta$, and the ATP levels in HeyA8 cells was significantly higher after inhibition of kinase activity in the rottlerin-treated group (Fig. 4C). There were significant reductions in the survival of HeyA8 cells by the supplementation of tipifarnib or rottlerin to FDI-6 treatment compared with a single FDI-6 treatment (Fig. 5A and C). However, the addition of sapitinib did not show a significant reduction in cell viability of HeyA8 cells (Fig. 5B). Unlike in HeyA8 cells, tipifarnib did not induce significant reduction in the cell viability of CAOV3 cells (Fig. 5D). In addition, there was no significant reduction in cell viability in SKOV3 cells, which showed lower FOXM1 expression (Fig. 5E-G). Fig. 6 shows that the cell viability of ovarian cancer cells when combined with FDI-6 treatment vs. treatment with the single agent tipifarnib, sapitinib or rottlerin. The present study also demonstrated the change in cell viability by microscopic imaging analysis of HeyA8, CAOV3 and SKOV3 cells (Fig. 7).

\section{Discussion}

Gormally et al (6) found that FDI-6 bound directly to FOXM1 protein and displaced it from its genomic targets in MCF-7 breast cancer cells and induced concomitant transcriptional downregulation. Since FDI-6 does not inhibit the synthesis of FOXM1 in cells, there is no decrease in FOXM1 expression induced by FDI- 6 based on western blot analysis. However, FOXM1 levels in the chromatin fractions decreased due to FOXM1 displacement from the DNA by FDI-6. The present study also demonstrated that FOXM1 expression in the chromatin fractions of HeyA8 cells was decreased by FDI-6 treatment. Inhibition of FOXM1 by FDI-6 induces inhibition of cancer cell proliferation $(6,18)$. Kalinichenko and Kalin (19) reported that FOXM1 is an important component of the KRAS/ERK signaling pathway in respiratory epithelial cells and inhibition of FOXM1 by FDI-6, either alone or in combination with other anticancer drugs, could be beneficial 
A

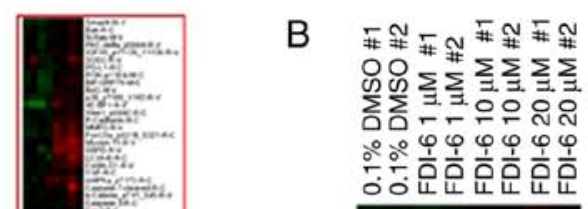

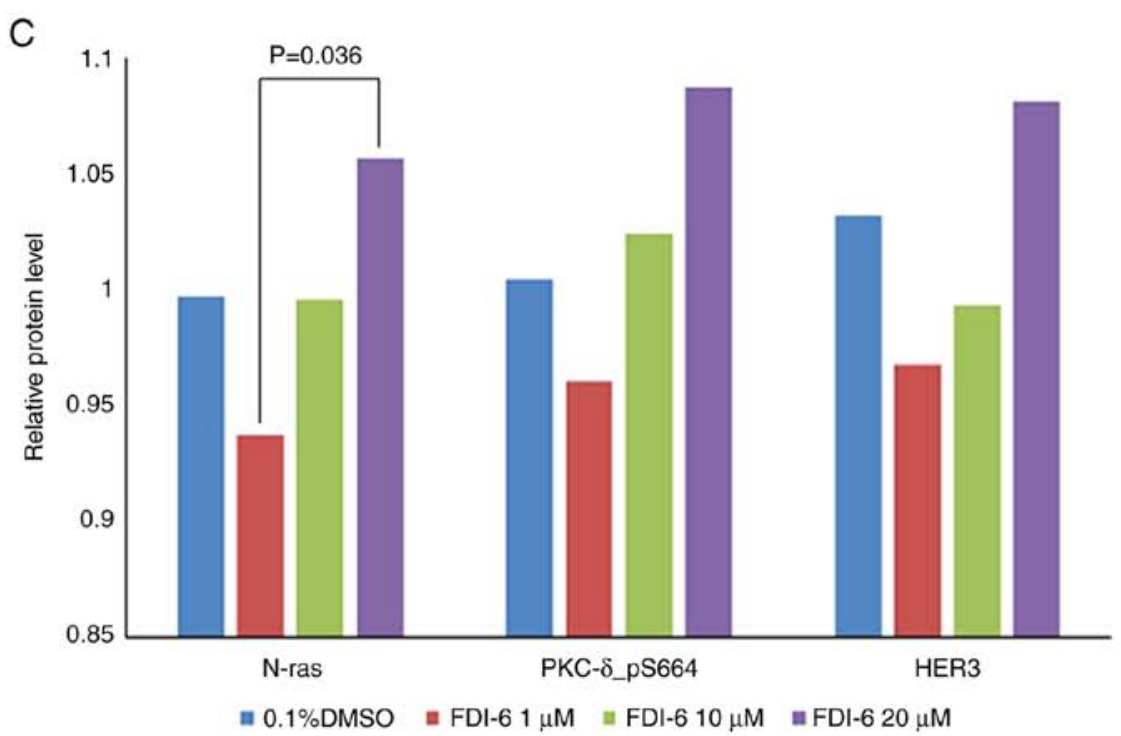

Figure 2. Reverse-phase protein array of HeyA8 cells. (A) HeyA8 cells were treated with FDI-6 in three-dimensional cell culture. Analyzed proteins are displayed on the right (green, downregulated; red, upregulated). The red rectangular area in A is zoomed in B. (B) Zoomed area showing FDI-6-specific upregulated proteins. The concentrations of FDI-6 are shown at the top of the heat map. (C) Expressional changes of proteins in lysates after FDI-6 treatment are shown in bar graphs. FDI-6, forkhead domain inhibitor-6. 
A
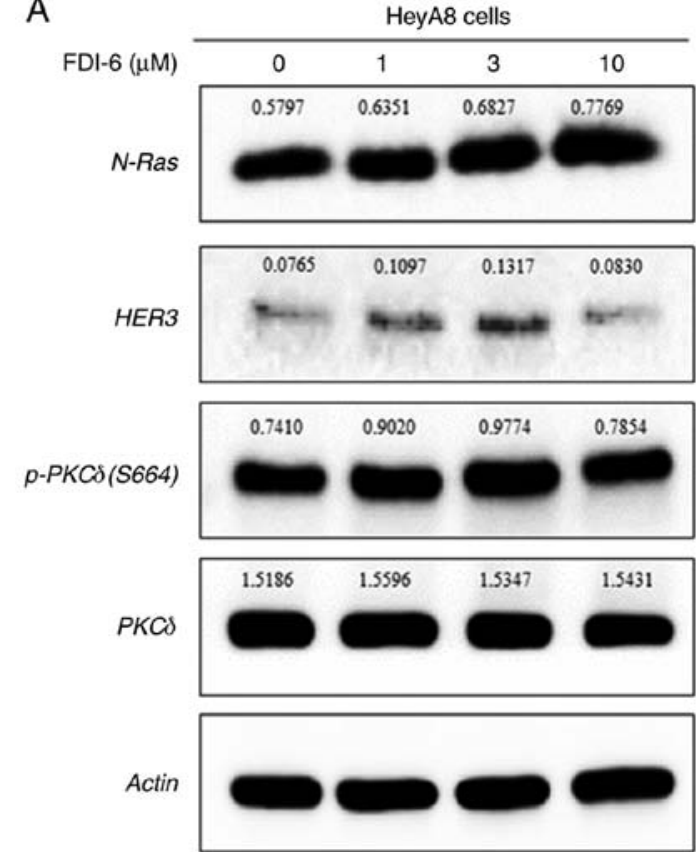

B
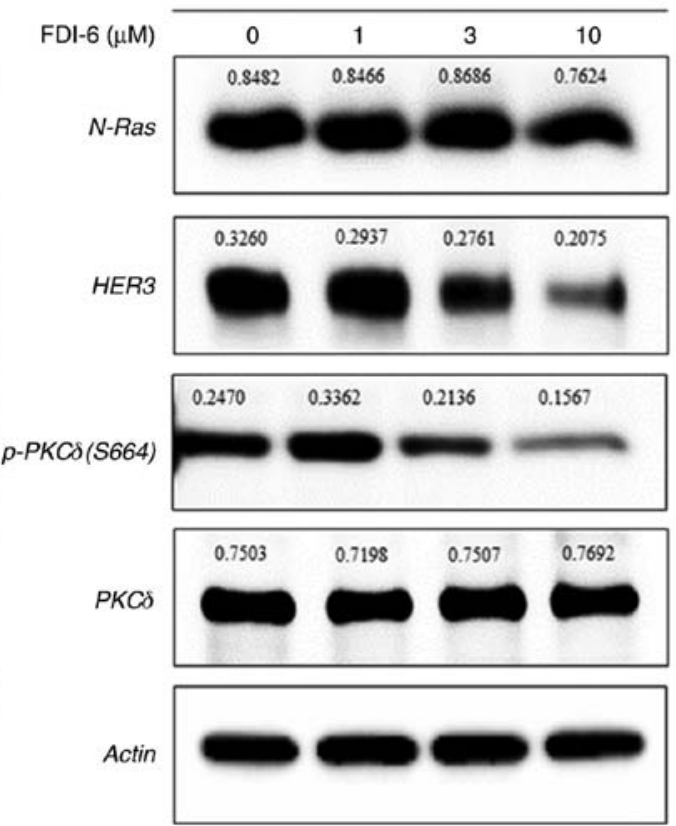

Figure 3. Protein expression in ovarian cancer cells treated with FDI-6. Western blot analysis of N-Ras, p-PKC (S664), PKC $\delta$ and HER3 proteins in (A) HeyA8 and (B) CAOV3 cells treated with 1, 3 or $10 \mu \mathrm{M}$ FDI-6 in three-dimensional cell culture for $24 \mathrm{~h}$. FDI-6, forkhead domain inhibitor-6.

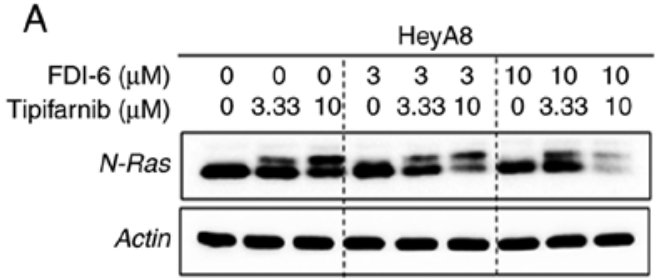

C

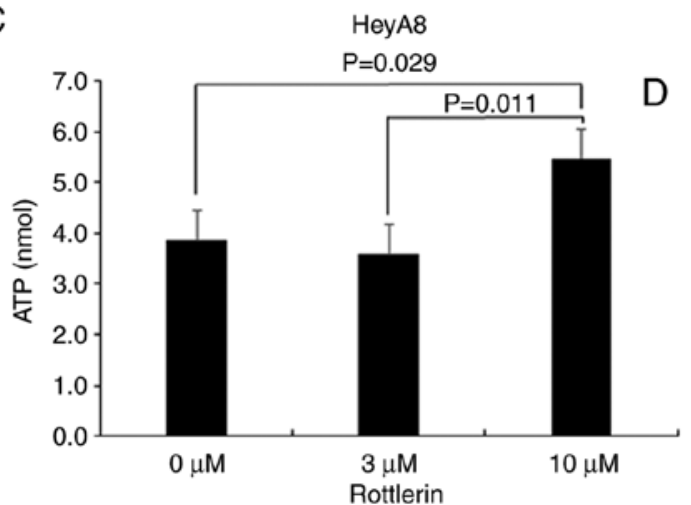

B

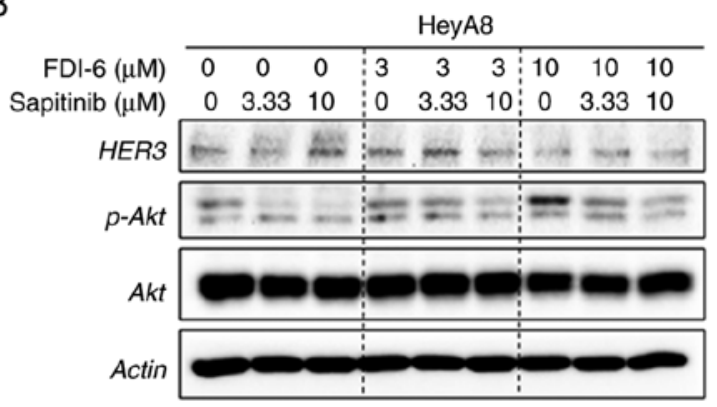
FDI- $6(\mu \mathrm{M}) \quad$\begin{tabular}{ccc:ccc:ccc} 
CAOV3 \\
\cline { 2 - 7 }
\end{tabular}

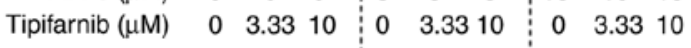

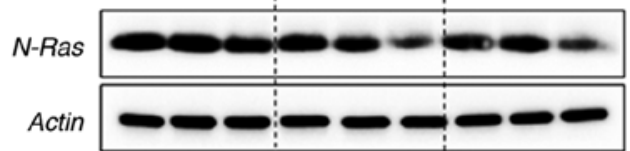

Figure 4. Proteins expression in ovarian cancer cells treated with inhibitors and FDI-6. (A) Western blot analysis of N-Ras expression in HeyA8 cells treated with tipifarnib and FDI-6 in three-dimensional cell culture. (B) Western blot analysis of proteins that are associated with the HER3 downstream signaling pathway in HeyA8 cells treated with sapitinib. (C) ATP levels in HeyA8 cells treated with rottlerin. Rottlerin inhibits the activity of the kinase that transfers a phosphate group to PKCס. Error bars represent standard deviation. All experiments were performed in duplicate. (D) Western blot analysis of N-Ras expression in CAOV3 cells treated with tipifarnib. FDI-6, forkhead domain inhibitor-6; p, phosphorylated.

for treatment of KRAS mutant non-small-cell lung cancers that are resistant to conventional chemotherapy.

The compensatory response is a mechanism by which cancer cells can avoid drug-mediated reactions. This response can modify the cell signaling pathway that is repressed by the targeted drug and activates the drug resistance process despite suppression of the oncogenic kinase (20). In our previous study, we observed upregulation of pS6 by adaptive signaling 
A

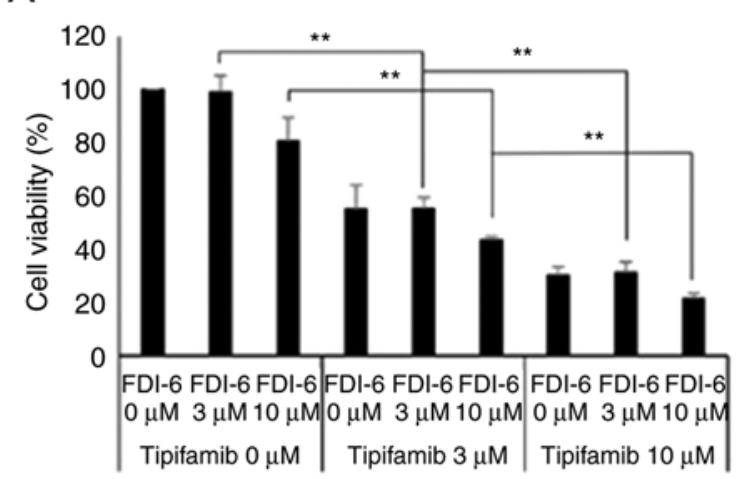

C

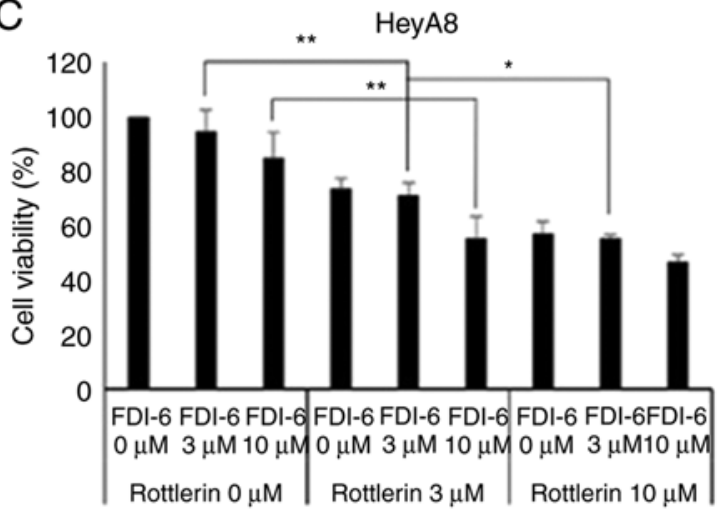

E

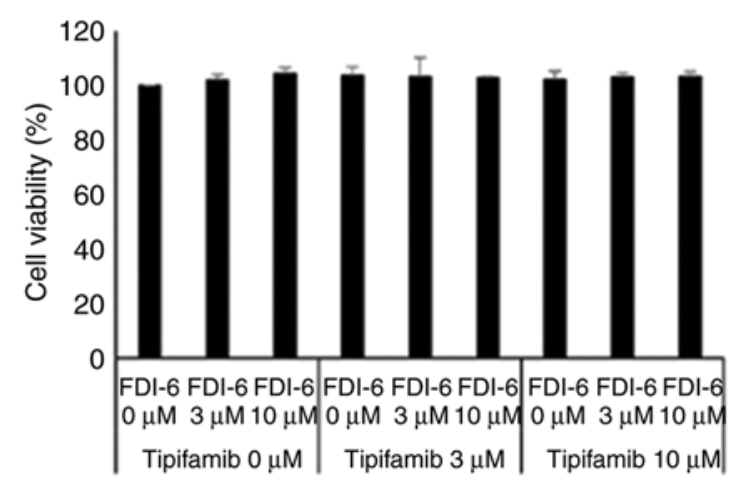

B

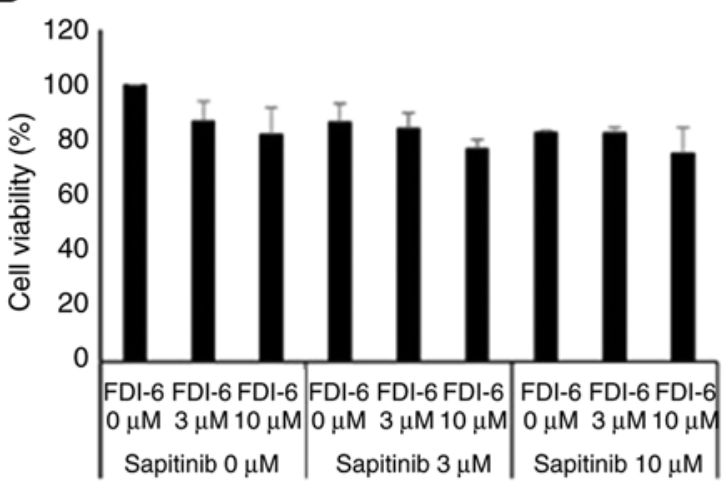

D

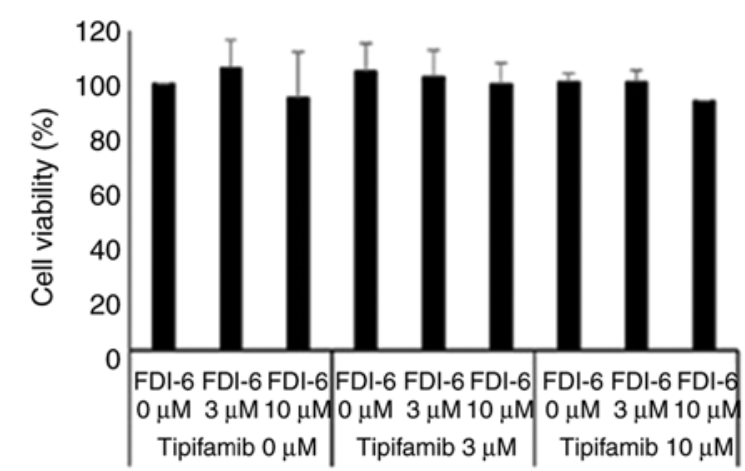

$\mathrm{F}$

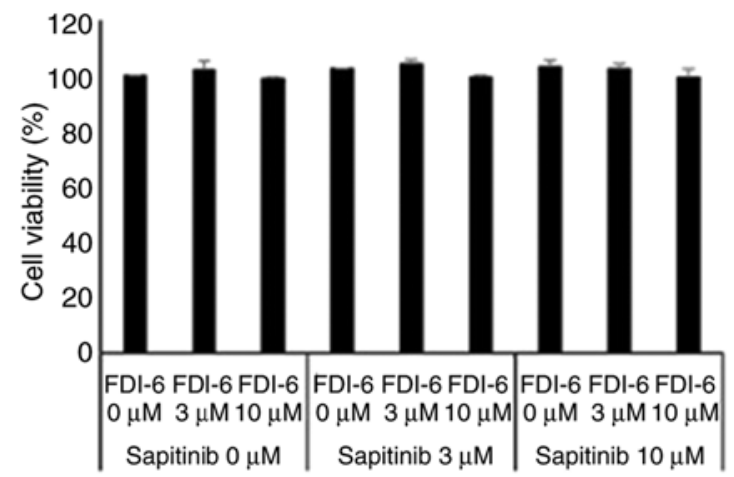

G

SKOV3

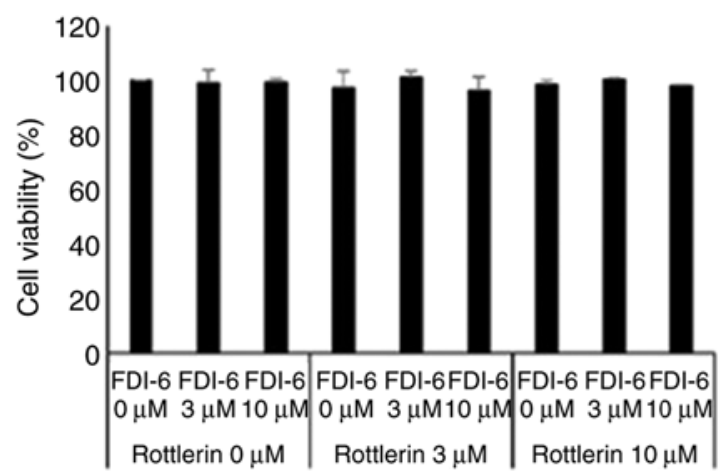

Figure 5. Viability of ovarian cancer cells treated with FDI-6 and inhibitors. Viability of HeyA8 cells following treatment with FDI-6 and inhibitors (A) tipifarnib, (B) sapitinib or (C) rottlerin in three-dimensional cell culture for $24 \mathrm{~h}$. (D) CAOV3 cell viability following treatment with FDI-6 and tipifarnib. Viability of SKOV3 cells after treatment with FDI-6 and inhibitors (E) tipifarnib, (F) sapitinib or (G) rottlerin. Error bars represent standard deviation and P-values were calculated using Tukey's Honest Significant Difference test. All experiments were performed in duplicate. ${ }^{*} \mathrm{P}<0.05$ and ${ }^{* *} \mathrm{P}<0.01$. FDI-6, forkhead domain inhibitor-6. 
A

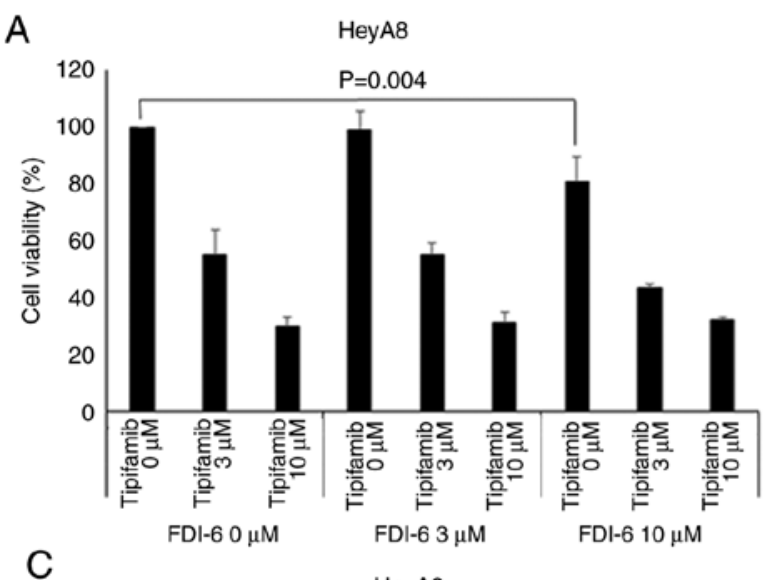

C

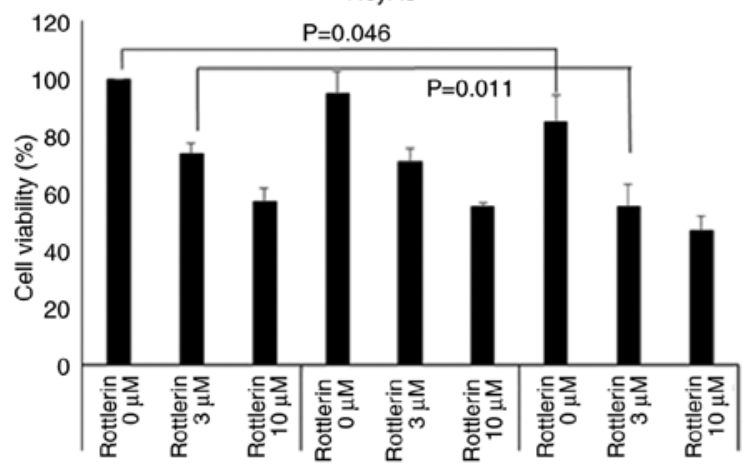

$\mathrm{E}$

FDI-6 $0 \mu \mathrm{M}$

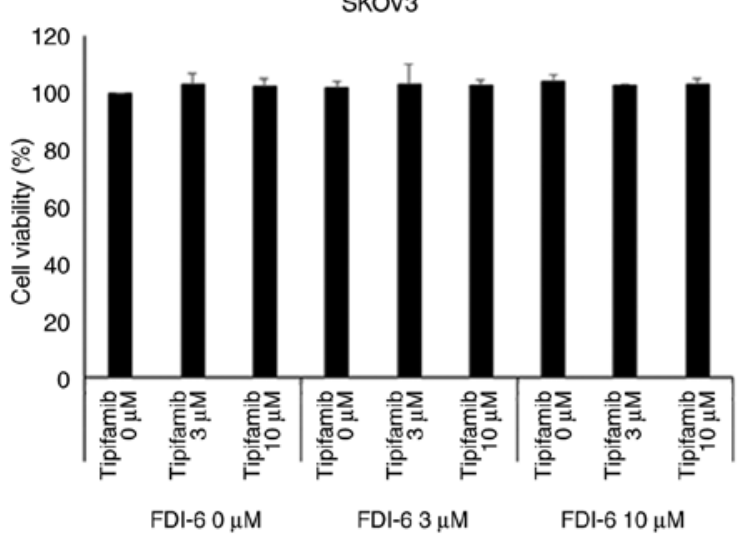

B

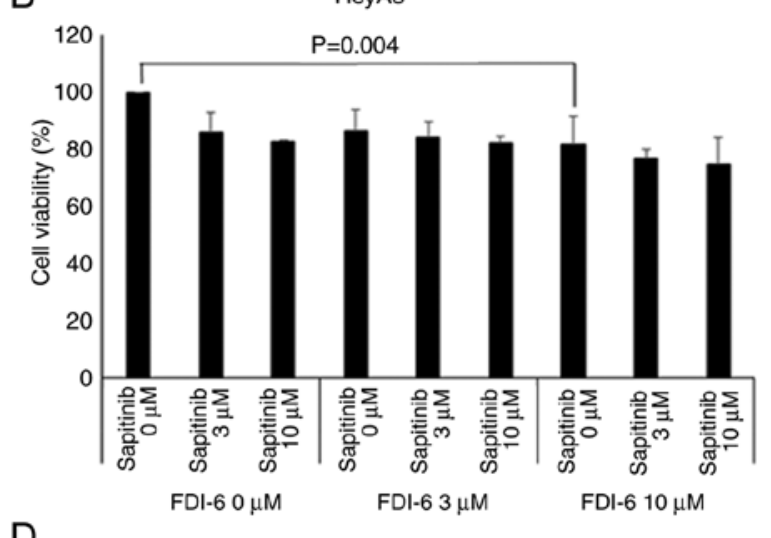

CAOV3

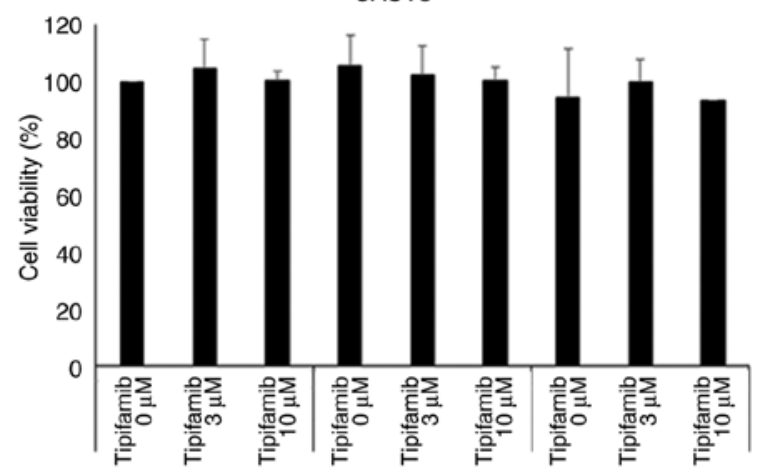

$\mathrm{F}$

FDI-6 $3 \mu \mathrm{M}$

FDI-6 $10 \mu \mathrm{M}$

SKOV3

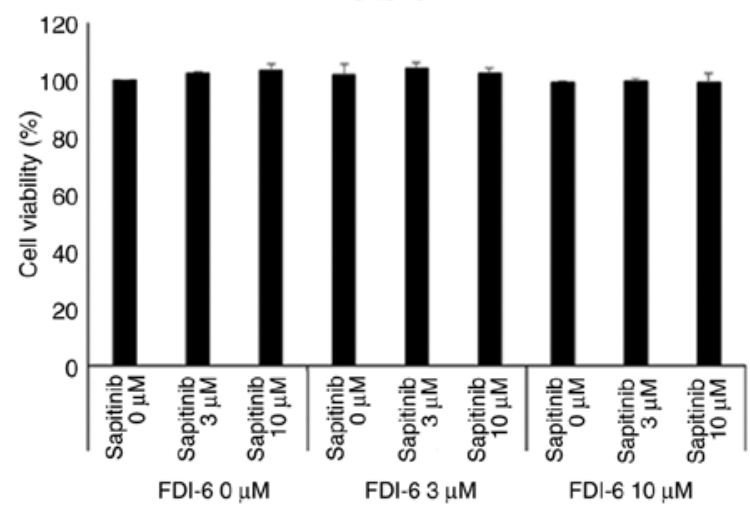

G

SKOV3

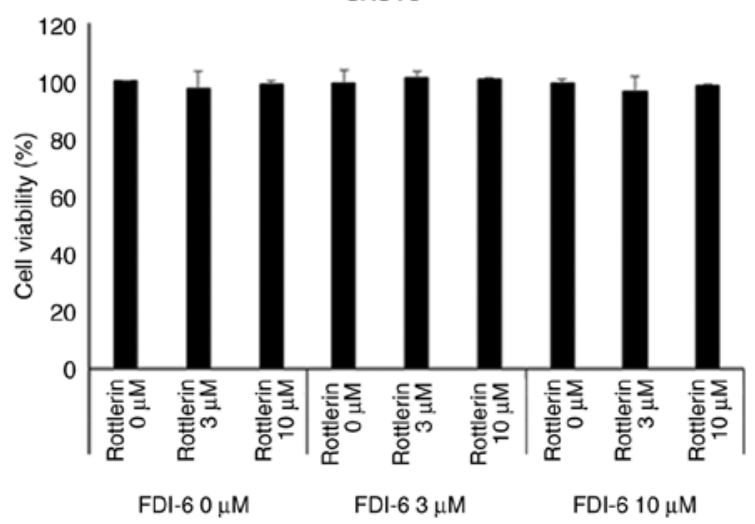

Figure 6. Viability of ovarian cancer cells after treatment with the combination of FDI-6 and inhibitors or inhibitor alone in three-dimensional cell culture for 24 h. Viability of HeyA8 cells following treatment with FDI-6 and inhibitors (A) tipifarnib, (B) sapitinib, (C) rottlerin or inhibitor alone. Viability of CAOV3 cells following treatment with FDI-6 and (D) tipifarnib or tipifarnib alone. Viability of SKOV3 cells following treatment with FDI-6 and (E) tipifarnib, (F) sapitinib, (G) rottlerin or inhibitor alone. Error bars represent the standard deviation and P-values were calculated using Tukey's Honest Significant Difference test. All experiments were performed in duplicate. FDI-6, forkhead domain inhibitor-6. 
A

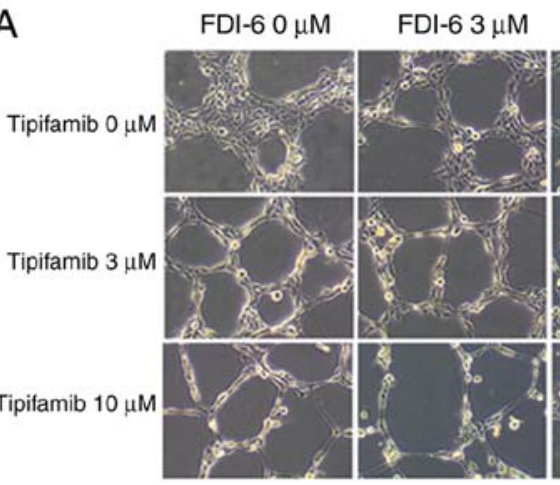

FDI-6 $10 \mu \mathrm{M}$

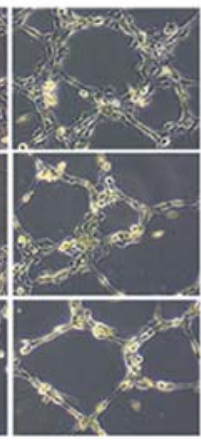

B

$\mathrm{FDI}-60 \mu \mathrm{M}$

FDI-6 $3 \mu \mathrm{M}$

FDI-6 $10 \mu \mathrm{M}$
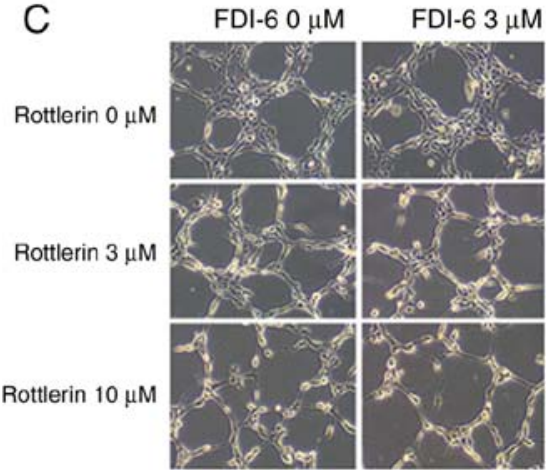

FDI-6 $10 \mu \mathrm{M}$

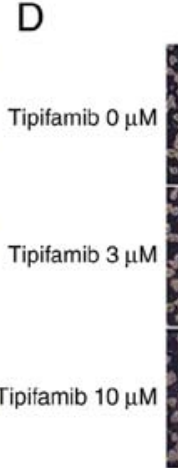

FDI-6 $0 \mu \mathrm{M} \quad$ FDI-6 $3 \mu \mathrm{M} \quad$ FDI-6 $10 \mu \mathrm{M}$
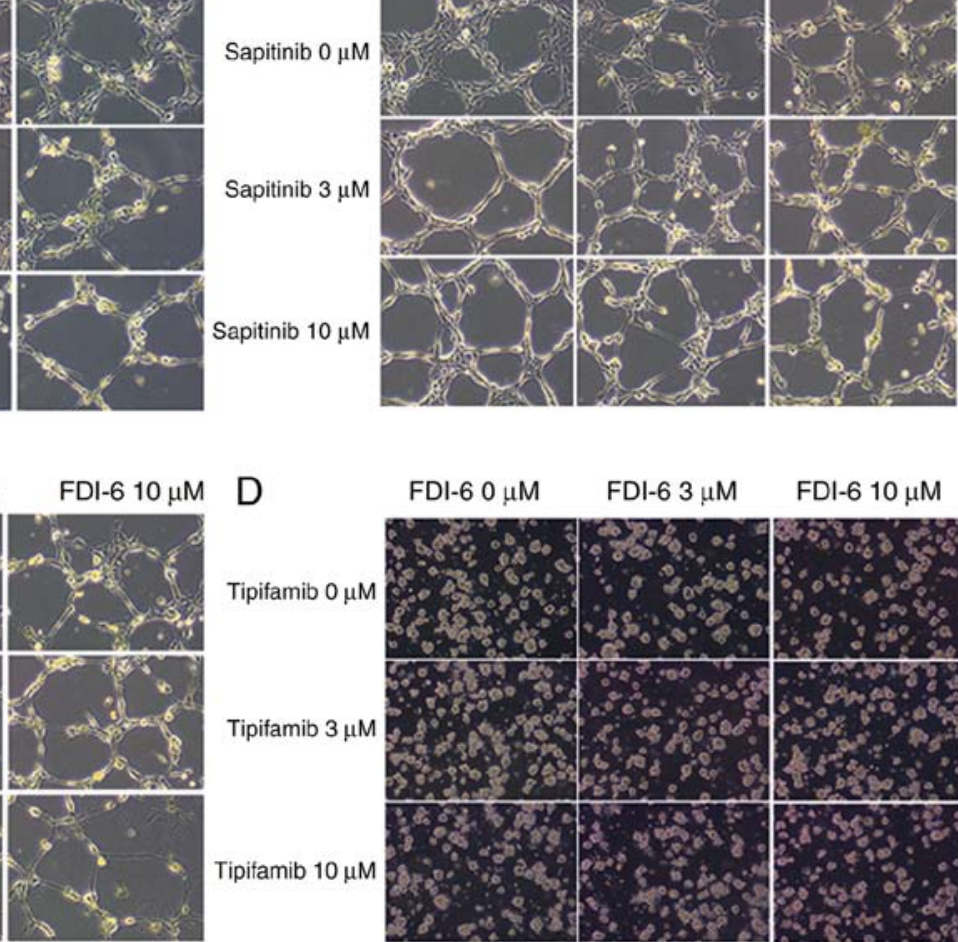

Figure 7. Microscopic imaging of ovarian cancer cells treated with FDI-6 and inhibitors. Microscopic changes in viability of HeyA8 cells following treatment with FDI-6 and inhibitors (A) tipifarnib, (B) sapitinib or (C) rottlerin in three-dimensional cell culture for $24 \mathrm{~h}$. (D) CAOV3 cell viability following treatment with FDI-6 and tipifarnib. Magnification, x100. FDI-6, forkhead domain inhibitor-6.

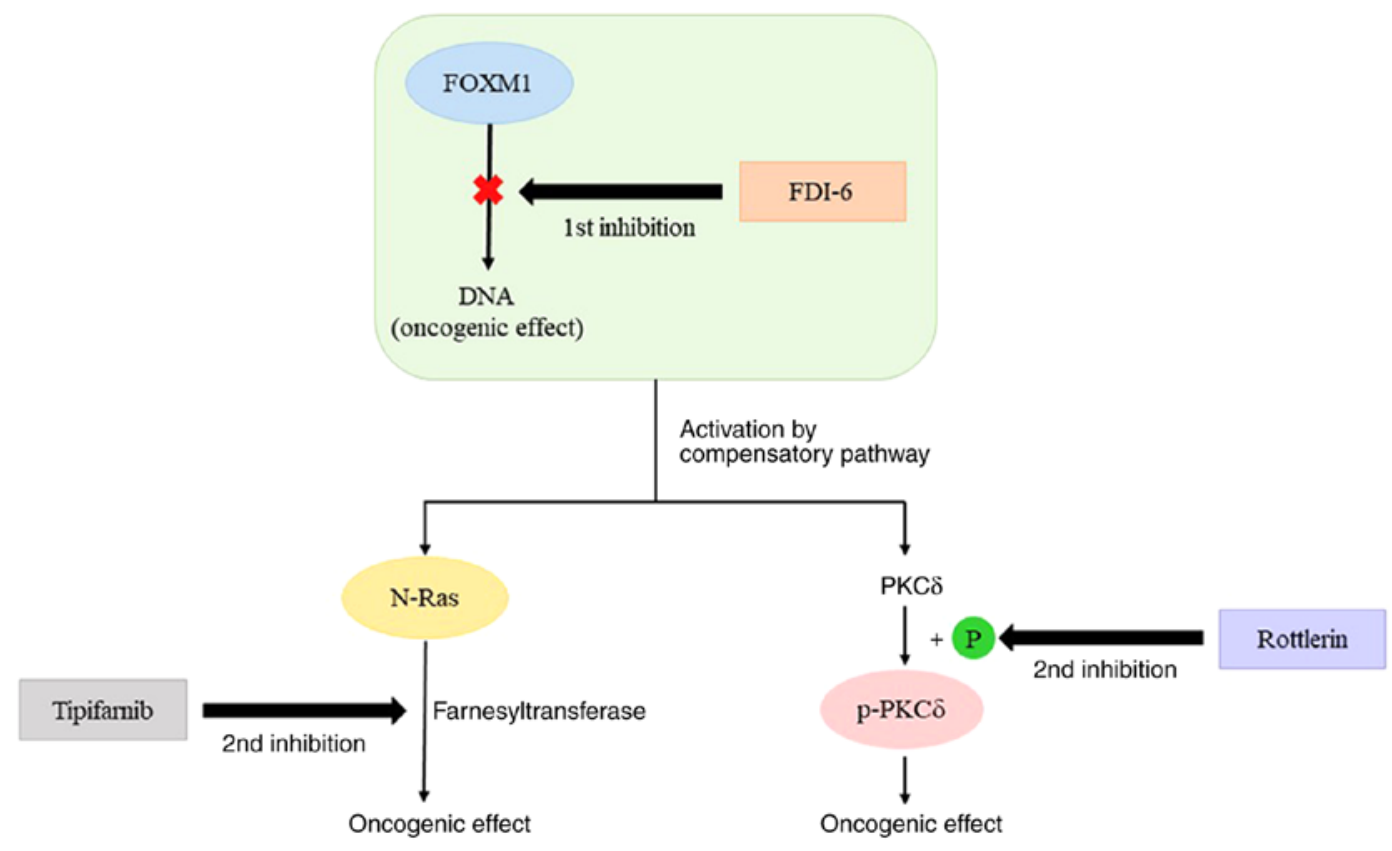

Figure 8. Compensatory pathway induced by FOXM1 inhibition in HeyA8 cancer cells. N-Ras and p-PKC $\delta$ were activated by a compensatory response. FDI-6, forkhead domain inhibitor-6; p, phosphorylated; FOXM1, forkhead box protein M1.

pathway response to paclitaxel in HeyA8 and SKOV3 ovarian cancer cells and demonstrated that the inhibition of pS6 by addition of BX795 or CCT128930 restricted the compensatory adaptive response to paclitaxel and further strengthened the effectiveness of paclitaxel (5). Turke et al (9) showed that the suppression of EGFR in non-small-cell lung carcinoma could lead to increased expression of MET receptor by the compensatory response. MET activation stimulates human epidermal growth factor 3 (ERBB3)/phosphatidylinositol 3 kinase $(\mathrm{PI} 3 \mathrm{~K}) /$ protein kinase B (AKT) signaling in EGFR mutant 
lung cancers and can result in resistance to EGFR kinase inhibitors. By inhibiting both EGFR and MET, the resistance to EGFR kinase inhibition could be resolved.

RPPA analysis is a screening method generally used to determine protein expression in cells. The present study assessed the approximate expression levels of proteins in ovarian cancer cells using RPPA analysis after FOXM1 inhibition by FDI-6. After selection of candidate proteins, the expression pattern was validated using western blot analysis. The protein detection methods are different between RPPA and western blot analyses, and thus, the results from these two analyses may be different. RPPA analysis is an excellent screening method but accuracy is rather insufficient than western blot analysis, and western blot analysis is usually used as a validation method for RPPA analysis. In contrast to the RPPA analysis, the western blot analysis showed that HER3 and p-PKCס (S664) expression was lower when induced by FDI-6 at a concentration of $10 \mu \mathrm{M}$ compared with a lower concentration of FDI-6.

Upon inhibition of FOXM1 using FDI-6 in HeyA8 cells, several proteins showed increased expression due to the compensatory adaptive response. The present study selected candidates with increased expression due to the compensatory pathway among proteins associated with the signaling pathway and excluded proteins for which no inhibitors, besides small interfering RNA or short hairpin RNA, were available. The expression of N-Ras, p-PKCס (S664) and HER3 tended to increase after FDI-6 treatment in HeyA8 cells; thus, these three proteins were selected. The N-Ras gene belongs to a class of genes known as oncogenes and encodes a protein called N-Ras, which is involved primarily in regulating cell division, cell differentiation and apoptosis of cells (21). Tipifarnib interferes with posttranslational modification of Ras and inhibits tumor cell growth. Tipifarnib is currently being evaluated in clinical trials for chronic myelomonocytic leukemia, acute myeloid leukemia and breast cancer alone or in combination with chemotherapy (22-24). Although the present study showed that the combination of tipifarnib and FDI- 6 was more effective than FDI-6 single treatment for growth restriction of HeyA8 cells, Yam et al (24) reported that the combination of tipifarnib and gemcitabine was not more effective than gemcitabine monotherapy in the treatment of metastatic breast cancer.

N-Ras and HER3 expression were increased by FDI-6 treatment at concentrations of 1 and $3 \mu \mathrm{M}$ but was downregulated at the higher concentration of $10 \mu \mathrm{M}$ FDI-6. Cell viability decreased to a greater extent in cells treated with the combination of the N-Ras inhibitor, tipifarnib, along with $10 \mu \mathrm{M}$ FDI-6 compared with tipifarnib plus 1 or $3 \mu \mathrm{M}$ FDI-6. These findings suggested that the concentration of $10 \mu \mathrm{M}$ FDI- 6 may be toxic to these cells and may decrease cell viability by both inhibiting cell signaling pathways and breaking cell structures directly. Tipifarnib inhibits farnesyltransferase, which is required to translocate N-Ras to the cell membrane (14). Following tipifarnib treatment, the expression of unfarnesylationed N-Ras increased and that of farnesylated N-Ras decreased. The upper band of N-Ras indicated unfarnesylated N-Ras. In CAOV3 cancer cells, tipifarnib was not effective and did not cleave $\mathrm{N}$-Ras into two parts. These data suggested that the function of tipifarnib differs between cell types $(14,25)$.
The PKC family is a group of serine and threonine kinases and plays a key role in the regulation of diverse cellular functions including proliferation, differentiation and tumorigenesis (26). Rottlerin was identified as a specific inhibitor of the novel PKC isoform, PKCס, and was shown to induce antiproliferative effects and apoptosis of human cancer cell lines (27). The inhibitory activity of rottlerin appears to be at least partially due to an interaction with the ATP-binding site of PKC (15). According to a manufacturer of rottlerin, when rottlerin inhibits kinase activity, fewer ATP molecules donate their phosphate groups. Assuming that the starting amount of ATP is fairly similar between the cells, the ATP amount will be higher in the rottlerin-treated group compared with the untreated control group. In the present study, the ATP amount did increase on increasing the concentration of rottlerin used to treat HeyA8 cells.

HER3 is a member of the EGFR/HER family and regulates cell division, proliferation, differentiation, angiogenesis and tumor progression (28). HER3 impairs kinase activity and heterodimerizes with HER2. HER3 heterodimerizes with receptor tyrosine kinases to activate oncogenic signaling via the PI3K/AKT pathway (17). Enhanced HER3 expression helps breast cancer cells bypass responsiveness to the estrogen receptor antagonist tamoxifen $(29,30)$. In the present study, HER3 expression increased in HeyA8 cells after treatment with FDI-6. However, the expression level was weaker than $\mathrm{N}-\mathrm{R}$ as and p-PKCס (S664) expression based on western blot analysis and the combination of sapitinib and FDI-6 was not significantly more effective compared with FDI-6 single treatment for growth restriction of HeyA8 cells.

Upon inhibition of FOXM1 using FDI-6 in HeyA8 cells, N-Ras, p-PKCס (S664) and HER3 showed increased expression by the compensatory adaptive response. Simultaneous inhibition of FOXM1 and the compensatory adaptive response via the combination of tipifarnib or rottlerin and FDI-6 was significantly more effective than FOXM1 single inhibition for growth restriction of HeyA8 cells (Fig. 8). However, the combination of FDI-6 and sapitinib did not induce a significant decrease in cell viability of HeyA8 cells, which showed a weak increase in HER3 expression by FOXM1 inhibition. Unlike in HeyA8 cells, FOXM1 inhibition using FDI-6 did not induce an increase in the expression of p-PKC $($ S664) and HER3, and compared with FDI-6 single treatment, the combination of tipifarnib and FDI- 6 did not show a significant reduction in cell viability of CAOV3 cells, in which FOXM1 expression was weaker compared with in HeyA8 cells. Furthermore, in SKOV3 cells, which showed weak FOXM1 expression, the combination of FDI-6 and tipifarnib, rottlerin, or sapitinib did not induce a significant decrease in cell viability.

The present study found that dual inhibition of FOXM1 and the compensatory adaptive response induced by FOXM1 inhibition increased the efficacy for growth restriction of ovarian cancer cells. These findings will aid in overcoming drug resistance, which is one of the issues in ovarian cancer therapy. However, further data via animal studies is needed to determine further clinical implications.

However, due to insufficient space and facilities, our laboratory were unable to use RNA interference or CRISPR on other living organisms, which is a limitation of the present study. 


\section{Acknowledgements}

We wish to acknowledge Dr Gordon Mills, who moved to Oregon Health and Science University from MD Anderson Cancer Center, for helping with the reverse-phase protein array. We also thank Dr Yun Yong Park (Asan Medical Center, Republic of Korea) for helping design the experiments.

\section{Funding}

We wish to acknowledge the financial support of the Institute of Clinical Medicine Research of Bucheon St. Mary's Hospital Research Fund (grant no. BCMC18AH09).

\section{Availability of data and materials}

The datasets used and/or analyzed during the current study are available from the corresponding author on reasonable request.

\section{Authors' contributions}

DL evaluated and analyzed the data and performed the experiments. WL and MK performed the experiments and statistical analysis. HNL conceived and designed the experiments, analyzed the data and wrote the manuscript. All authors read and approved the final manuscript.

\section{Ethics approval and consent to participate}

This study was approved by the Institutional Review Board of the Catholic University of Korea, Bucheon, Korea (approval no. HC18EESI0095).

\section{Patient consent for publication}

Not applicable.

\section{Competing interests}

The authors declare that they have no competing interests.

\section{References}

1. Lheureux S, Gourley C, Vergote I and Oza AM: Epithelial ovarian cancer. Lancet 393: 1240-1253, 2019.

2. Ferlay J, Soerjomataram I, Dikshit R, Eser S, Mathers C, Rebelo M, Parkin DM, Forman D and Bray F: Cancer incidence and mortality worldwide: Sources, methods and major patterns in GLOBOCAN 2012. Int J Cancer 136: E359-E386, 2015.

3. Berek JS: Ovarian, fallopian tube and peritoneal cancer. In: Berek and Novak's Gynecology, 15th edition Berek JS, Longacre TA and Friedlander M (eds). Wolters Kluwer/Lippincott Williams \& Wilkins, Philadelphia, PA, pp1350-1427, 2011.

4. Cancer Genome Atlas Research Network. Integrated genomic analyses of ovarian carcinoma. Nature 474: 609-615, 2011.

5. Choi JI, Park SH, Lee HJ, Lee DW and Lee HN: Inhibition of phospho-S6 kinase, a protein involved in the compensatory adaptive response, increases the efficacy of paclitaxel in reducing the viability of matrix-attached ovarian cancer cells. PLoS One 11: e0155052, 2016

6. Gormally MV, Dexheimer TS, Marsico G, Sanders DA, Lowe C, Matak-Vinković D, Michael S, Jadhav A, Rai G, Maloney DJ, et al: Suppression of the FOXM1 transcriptional programme via novel small molecule inhibition. Nat Commun 5: 5165, 2014.
7. Koo CY, Muir KW and Lam EWF: FOXM1: From cancer initiation to progression and treatment. Biochim Biophys Acta 1819: 28-37, 2012.

8. Chan DW, Hui WW, Cai PC, Liu MX, Yung MM, Mak CS, Leung TH, Chan KK and Ngan HY: Targeting GRB7/ERK/FOXM1 signaling pathway impairs aggressiveness of ovarian cancer cells. PLoS One 7: e52578, 2012.

9. Turke AB, Zejnullahu K, Wu YL, Song Y, Dias-Santagata D, Lifshits E, Toschi L, Rogers A, Mok T, Sequist L, et al: Preexistence and clonal selection of MET amplification in EGFR mutant NSCLC. Cancer Cell 17: 77-88, 2010.

10. Debnath J and Brugge JS: Modelling glandular epithelial cancers in three-dimensional cultures. Nat Rev Cancer 5: 675-688, 2005.

11. Weigelt B and Bissell MJ: Unraveling the microenvironmental influences on the normal mammary gland and breast cancer. Semin Cancer Biol 18: 311-321, 2008.

12. Yamada KM and Cukierman E: Modeling tissue morphogenesis and cancer in 3D. Cell 130: 601-610, 2007.

13. Buick RN, Pullano R and Trent JM: Comparative properties of five human ovarian adenocarcinoma cell lines. Cancer Res 45: 3668-3676, 1985

14. Appels NM, Beijnen JH and Schellens JH: Development of farnesyl transferase inhibitors: A review. Oncologist 10: 565-578, 2005.

15. Gschwendt M, Müller HJ, Kielbassa K, Zang R, Kittstein W, Rincke $G$ and Marks F: Rottlerin, a novel protein kinase inhibitor. Biochem Biophys Res Commun 199: 93-98, 1994.

16. Scheipl S, Barnard M, Cottone L, Jorgensen M, Drewry DH, Zuercher WJ, Turlais F, Ye H, Leite AP, Smith JA, et al: EGFR inhibitors identified as a potential treatment for chordoma in a focused compound screen. J Pathol 239: 320-334, 2016.

17. Mishra R, Patel H, Alanazi S, Yuan L and Garrett JT: HER3 signaling and targeted therapy in cancer. Oncol Rev 12: 355, 2018.

18. Tabatabaei-Dakhili SA, Aguayo-Ortiz R, Domínguez L and Velázquez-Martínez CA: Untying the knot of transcription factor druggability: Molecular modeling study of FOXM1 inhibitors. J Mol Graph Model 80: 197-210, 2018.

19. Kalinichenko VV and Kalin TV: Is there potential to target FOXM1 for 'undruggable' lung cancers? Expert Opin Ther Targets 19: 865-867, 2015.

20. Trusolino L and Bertotti A: Compensatory pathways in oncogenic kinase signaling and resistance to targeted therapies: Six degrees of separation. Cancer Discov 2: 876-880, 2012.

21. Uprety D and Adjei AA: KRAS: From undruggable to a druggable cancer target. Cancer Treat Rev 89: 102070, 2020.

22. Elmariah H and DeZern AE: Chronic myelomonocytic leukemia: 2018 update to prognosis and treatment. Curr Hematol Malig Rep 14: 154-163, 2019.

23. Erba HP, Othus M, Walter RB, Kirschbaum MH, Tallman MS, Larson RA, Slovak ML, Kopecky KJ, Gundacker HM and Appelbaum FR: Four different regimens of farnesyltransferase inhibitor tipifarnib in older, untreated acute myeloid leukemia patients: North American Intergroup Phase II study SWOG S0432. Leuk Res 38: 329-333, 2014.

24. Yam C, Murthy RK, Valero V, Szklaruk J, Shroff GS, Stalzer CJ, Buzdar AU, Murray JL, Yang W, Hortobagyi GN, et al: A phase II study of tipifarnib and gemcitabine in metastatic breast cancer. Invest New Drugs 36: 299-306, 2018.

25. Vasan N, Boyer JL and Herbst RS: A RAS renaissance: Emerging targeted therapies for KRAS-mutated non-small cell lung cancer. Clin Cancer Res 20: 3921-30, 2014.

26. Giorgi C, Agnoletto C, Baldini C, Bononi A, Bonora M, Marchi S, Missiroli S, Patergnani S, Poletti F, Rimessi A, et al: Redox control of protein kinase C: Cell- and disease-specific aspects. Antioxid Redox Signal 13: 1051-1085, 2010.

27. Soltoff SP: Rottlerin: An inappropriate and ineffective inhibitor of PKCdelta. Trends Pharmacol Sci 28: 453-458, 2007.

28. Hynes NE and MacDonald G: ErbB receptors and signaling pathways in cancer. Curr Opin Cell Biol 21: 177-184, 2009.

29. Newby JC, Johnston SR, Smith IE and Dowsett M: Expression of epidermal growth factor receptor and c-erbB2 during the development of tamoxifen resistance in human breast cancer. Clin Cancer Res 3: 1643-1651, 1997.

30. Shou J, Massarweh S, Osborne CK, Wakeling AE, Ali S, Weiss H and Schiff R: Mechanisms of tamoxifen resistance: Increased estrogen receptor-HER2/neu cross-talk in ER/HER2-positive breast cancer. J Natl Cancer Inst 96: 926-935, 2004. 